\title{
Effect of music on submaximal cycling
}

\author{
Nicola A Schie (BSc Physiotherapy, MSc Physiotherapy) ${ }^{1}$ \\ Aimee Stewart (BSc Physiotherapy, DPE, MSc (Medicine), PhD) ${ }^{1}$ \\ Pieter Becker (PhD) ${ }^{2}$ \\ Geoff G Rogers (PhD) ${ }^{3}$ \\ ${ }^{1}$ University of the Witwatersrand, Faculty of Health Sciences, School of Therapeutic Sciences \\ ${ }^{2}$ South African Medical Research Council, Biostatistical Services and Training \\ ${ }^{3}$ University of the Witwatersrand, Faculty of Health Sciences, School of Physiology
}

\begin{abstract}
Objective. Athletes frequently report training to music, yet there have been relatively few studies that have addressed the benefit of exercising with music.

Design. Volunteer men and women $(N=30)$, aged between 18 and 40 years, performed an initial familiarisation session. Part of this session involved the measurement of maximal oxygen consumption. With at least a 48-hour intervening period, this was then followed by a first 20-minute submaximal cycling session, at $80 \%$ of maximal oxygen consumption. At least 48 hours later a second submaximal cycling session was performed. Subjects were randomly divided into two groups. Group A cycled without music and group B cycled with music for the first submaximal cycling session. Subjects underwent the same testing procedure for the second submaximal cycling session, but this time group A cycled to music and group B cycled without music. Subjects served as their own controls.
\end{abstract}

Setting. The study was performed in the physiology exercise laboratory, at the University of the Witwatersrand.

Main outcome measures. During the submaximal sessions heart rate, perceived exertion (Borg scale) and plasma lactate concentration were assessed. Subjects completed a post-test questionnaire once both submaximal cycling sessions were completed.

\section{CORRESPONDENCE:}

Nicola Schie

2 The Grove

Golders Green

London NW11 9SH

Tel: +44 7725665320

E-mail: Nicola.schie@gmail.com
Results. There were no significant differences in physiological variables (change in plasma lactate and heart rate), nor were there any significant differences in Borg scale ratings when the subjects cycled with and without music. However, according to the post-test questionnaire $67 \%$ of subjects identified the cycling session with music to be easier than the session without music.

Conclusion. Listening to music while performing submaximal cycling resulted in no physiological benefit. Yet, the cycling session done in conjunction with music was deemed, by the majority of the subjects, to be easier than the cycling session without music.

\section{Introduction}

With increasing interest and emphasis placed on sport, athletes are continually searching for anything that will give them a more competitive edge. Next to cycling hardware, the cyclist is most concerned about training schedules. If music were added to training, then training could be perceived as less monotonous and less arduous. Thus the inclusion of music into training programmes may result in increased exercise effort, training adherence and a possible positive effect on performance. . $^{2,9}$

Previous studies have yielded contradictory findings. Most of the preceding work has concentrated on physiological and subjective responses to music, while performing either aerobic or anaerobic exercise. ${ }^{1,7,8}$ None of the previous studies has measured the effect of music on a specific athletic group, like cyclists.

It is common practice to include background music while exercising, ${ }^{5}$ as it lends to the pacing of movement, as well as enhances emotive and distractive elements in the athlete. ${ }^{9,10}$ Cycling, as both a hobby and a sport, is gaining popularity. In order to become accomplished, cyclists need to spend many hours on a bicycle, whether it is on the road or on an indoor trainer. Incorporating music with training will most likely limit boredom and loss of motivation in most cyclists, and help maintain training momentum.

The aim of this study was to investigate whether music causes changes in physiological and psychological variables during submaximal cycling. 


\section{Methods}

All procedures used in this study have been approved by the committee for research on human subjects, at the University of the Witwatersrand, Johannesburg.

\section{Study design}

A two-period cross-over design was undertaken (Fig. 1).

$1^{\text {st }}$ SUBMAXIMAL
CYCLING SESSION

Fig. 1. Schematic representation of two-period cross-over design.

\section{Subjects}

To calculate the sample size, a change on the Borg scale was used as the primary efficiency variable. In accordance, a sample of 28 cyclists was shown by a power calculation to provide at least $90 \%$ power to detect an experimentally relevant difference between the two groups. A total of 30 cyclists volunteered and provided written consent to participate in this study. Subjects were excluded from the study if they had any underlying systemic disease, any contraindication to participating in submaximal exercise, or any acute injury that could interfere with cycling performance. Professional cyclists were excluded from this study.

\section{General procedures}

The study was performed in an exercise laboratory. Throughout the study the environment within the laboratory remained at room temperature $\left(21-23^{\circ} \mathrm{C}\right)$, and an electric fan was used to facilitate sweat evaporation. The laboratory was kept as visually sterile as possible.

All subjects participated in an initial familiarisation and measurement of maximal oxygen consumption session, followed by two separate submaximal cycling sessions. The three sessions were planned at least 48 hours apart and each session was scheduled at the same time of the day. All subjects were instructed to refrain from eating or drinking (except for water) for at least 2 hours prior to testing. In addition, subjects were asked not to exercise for 12 hours before the sessions.

\section{Familiarisation and maximal oxygen consumption session}

During this session subjects were asked to read and sign informed consent. In addition, they were asked to complete a medical screening ${ }^{6}$ and a pretest questionnaire. The medical questionnaire allowed for detection of any past and present medical conditions, as well as to confirm that no undesirable substances had been ingested. The pretest questionnaire obtained an exercise history and biometric data from each subject.

After the collection of anthropometric data, maximal oxygen consumption $\left(\mathrm{VO}_{2 \max }\right)$ was determined using an intermittent, incremental protocol on a cycle ergometer (Dynavit Meditronic, Keiper Dynavit Company, Kaiserlauten, West Germany) and a calibrated metabolic cart (Oxycon 4, Mjinhardt, Netherlands) to measure oxygen consumption.

The $\mathrm{VO}_{2 \text { max }}$ test consisted of a 10-minute warm-up at 100 Watts $(\mathrm{W})$, followed by a 5 -minute workload of $150 \mathrm{~W}$. For the measurement of $\mathrm{V}_{2}$ max starting load varied depending on the subject's cycling ability. Workloads were increased in $20 \mathrm{~W}$ stages. Each load lasted for 3 minutes or until the subject was too exhausted to carry on pedalling, followed by a 10-15-minute rest period. Maximal oxygen consumption was taken as the average of the oxygen consumptions measured, when an increment of 20 $\mathrm{W}$ resulted in a $\mathrm{VO}_{2}$ which differed by less than $1 \mathrm{ml} / \mathrm{kg}$. min from the previous $\mathrm{VO}_{2}$ measurement.

\section{Submaximal cycling sessions}

For the submaximal cycling sessions the subjects secured their own bicycles onto the cyclosimulator (Model: Cat-Eye, Osaka, Japan), which was calibrated before the start of the study. A resting, finger-prick lactate concentration measurement was taken, using a hand-held lactate analyser (Accusport Boehringer Mannheim, Germany). Once on their bicycles, the CD player (Discman, Sony D-121 MEGA BASS, Japan) was linked up to lightweight earphones which were securely placed in the subject's ears, regardless of whether the cycling session was with or without music. The subjects were allowed to adjust the volume prior to the start of the cycling session. Subjects were also linked up to the metabolic cart, via a two-way non-rebreathing valve (Hans Rudolph Inc. Kansas City, Missouri, USA).

The cycling session began with a brief warm-up (2 - 8 minutes). The warm-up ended once subjects reached $80 \%$ of their maximal oxygen consumption. During the 20 minutes of submaximal cycling, subjects were asked to keep within a $78-82 \%$ range of their $\mathrm{VO}_{2 \max }$. Subjects were allowed to view this information on the Oxycon monitor. Verbal encouragement was only given when subjects were not maintaining their work intensity range. The first submaximal cycling session was conducted without music for group A and with music for group B. The music used was identical and in the same order for all subjects. Five songs, Imagine (John Lennon), Bohemian Rhapsody (Queen), Summer of '69 (Bryan Adams), Sunday Bloody Sunday (U2) and How you remind me (Nickelback), were randomly selected out of the top ten songs of all time, voted for in a radio poll at the end of 2002. This ensured that the music that was played during the study consisted of varied tempos. The radio station's audience is of a similar age group to that of the subjects who participated in this study.

During the cycling sessions, subjects were blinded as to what their heart rate, distance and speed were. Subjects were only conscious of the time and their oxygen consumption. After every 2-minute interval and on completion of the test (starting at time 2 minutes and ending time 20 minutes), heart rate (beats per minute) and Borg scale readings were recorded. A Polar heart 
rate monitor (Model M21; Oy, Finland) was used to record the subject's heart rate. Instantaneous perception of exertion was measured using the 10-point Borg scale ${ }^{4}$ Distance and time were measured by the cyclosimulator.

Shortly after the completion of the cycling session, before the cyclists had dismounted from their bicycles, another finger-prick lactate concentration measurement was taken.

The identical procedure was followed in the second submaximal cycling session. The second submaximal cycling session took place at least 48 hours after the first session. Group A now cycled with music, and group B cycled without music.

\section{Statistical analysis}

The difference between 'with' and 'without' music with respect to heart rate, Borg scale and change in plasma lactate concentration were analysed using a 2-way analysis of variance (ANOVA), adjusting for the baseline which was taken to be 2 minutes after the start of exercise. The data were analysed and corrected for both fixed and random effects. Differences were accepted as significant at $p<0.05$.

\section{Results}

The physical characteristics (means \pm standard deviations) of all the subjects are illustrated in Table I.

According to the pretest questionnaire, most subjects cycled more than $100 \mathrm{~km}$ per week, and the majority cycled, on average, on 3 different occasions during the week. There were no differences between the groups with regard to physical characteristics, training histories and oxygen consumption measured during exercise.

There was no significant difference in the change in blood lactate concentration (Table II), heart rate (Table III) and Borg scale (Table IV) when comparing the cycling session with music to the cycling session without music.

The subject's perception of the cycling sessions, with music and without music, was inconsistent with the objective findings. Exercising to music was perceived as being significantly less

TABLE I. Physical characteristics of subjects (group A and $B$ combined, $N=30$ )

\begin{tabular}{lll}
\hline & Mean & \pm SD \\
\hline Age (years) & 29.3 & \pm 5.1 \\
Weight $(\mathrm{kg})$ & 70.4 & \pm 10.6 \\
Height $(\mathrm{cm})$ & 174.3 & \pm 7.1 \\
$\mathrm{VO}_{2 \max }\left(\mathrm{ml} \mathrm{min}{ }^{-1} \cdot \mathrm{kg}^{-1}\right)$ & 52.0 & \pm 8.6 \\
$\mathrm{SD}=$ standard deviation. & & \\
\hline
\end{tabular}

TABLE II. Mean change in plasma lactate concentration $\left(\mathrm{mmol}^{-1}\right)$ before and after cycling at $80 \% \mathrm{VO}_{2}$ with and without music $(N=30)$

\begin{tabular}{llllll}
\hline With music & \pm SD & Without music & \pm SD & $p$-value & CoD (\%) \\
\hline 5.4 & \pm 2.1 & 5.8 & \pm 2.1 & 0.32 & $86.3 \%$ \\
$\begin{array}{l}\text { Change in plasma lactate }=\text { plasma lactate concentration measured after exercise } \\
\text { minus plasma lactate concentration before exercise; SD = standard deviation; CoD }= \\
\text { coefficient of determination. }\end{array}$
\end{tabular}

TABLE III. Means for heart rate responses while cycling at $80 \% \mathrm{VO}_{2 \max }$ with and without music (baseline adjusted to 2 minutes) $(N=30)$

\begin{tabular}{lllllll}
\hline $\begin{array}{l}\text { Time } \\
\text { (min) }\end{array}$ & $\begin{array}{l}\text { With } \\
\text { music }\end{array}$ & \pm SD & $\begin{array}{l}\text { Without } \\
\text { music }\end{array}$ & \pm SD & $\boldsymbol{p}$-value & $\begin{array}{l}\text { CoD } \\
(\%)\end{array}$ \\
\hline 4 & 150.9 & \pm 8.0 & 151.0 & \pm 8.0 & 1.0 & 91.0 \\
20 & 169.7 & \pm 6.9 & 167.7 & \pm 6.9 & 0.07 & 92.8 \\
\multicolumn{7}{l}{ Min = minutes; SD = standard deviation; $\mathrm{CoD}=$ coefficient of determination. }
\end{tabular}

TABLE IV. Means for rating of perceived exertion (Borg scale) while cycling at $80 \% \quad \mathrm{VO}_{2 \max }$ with and without music (baseline adjusted to 2 minutes) $(N=30)$

\begin{tabular}{lllllll}
\hline $\begin{array}{l}\text { Time } \\
(\mathrm{min})\end{array}$ & $\begin{array}{l}\text { With } \\
\text { music }\end{array}$ & $\pm \mathrm{SD}$ & $\begin{array}{l}\text { Without } \\
\text { music }\end{array}$ & $\pm \mathrm{SD}$ & p-value & $\begin{array}{l}\text { CoD } \\
(\%)\end{array}$ \\
\hline 4 & 3.4 & \pm 0.8 & 3.4 & \pm 0.8 & 0.67 & 80.0 \\
20 & 4.8 & \pm 1.0 & 4.6 & \pm 1.0 & 0.32 & 89.6
\end{tabular}

$\mathrm{Min}=$ minutes $; \mathrm{SD}=$ standard deviation $; \mathrm{CoD}=$ coefficient of determination

demanding than exercising without music. The majority of subjects $(67 \%)$ identified the cycling session with music as the easier of the two cycling sessions, compared with $17 \%$ who found cycling without music easier and $17 \%$ who rated the sessions the same.

Most $(57 \%)$ subjects found the music to be overall stimulating, while $27 \%$ indicated that overall the music was relaxing. Some $(6 \%)$ said that they found the music to be both stimulating and relaxing and the last $10 \%$ expressed that the music evoked some other sensation.

\section{Discussion}

The most interesting finding in this study was the inconsistency between the subjects' overall perception of the cycling sessions and their instantaneous perceived exertion at 2-minute intervals. Even though there were no significant physiological or instantaneous ratings of perceived exertion differences between measurements made at 2-minute intervals during the cycling with or without music, $67 \%$ of subjects indicated that the cycling session with music was substantially easier than the session without music. This inconsistency highlights that there must be psychological influences occurring during submaximal exercise. It is possible that the subjects enjoyed the cycling session with music more than without music, and thus they perceived it to be easier. The music may have generated positive emotional states rather than acting purely as a distracter.

Fifty seven per cent of subjects found the music to be stimulating. This may have contributed to subjects' finding the cycling session with music to be easier. The music in this study was deliberately made up of varying tempos, so that the tempo of the selected songs would not influence the objectivity of the results. Consequently, one would have expected that more subjects would have found the music to be a combination of stimulating and relaxing sounds.

Analysis of the subjects' heart rate failed to produce any significant differences. Twenty minutes of cycling may not have been enough of an extended physiological strain. The reason why 20 minutes was chosen was because many similar 
studies $^{3,7,11}$ utilised this particular time period for their testing and got favourable results. Subjects in this study indicated that the music was stimulating, and that may have been the reason why at 20 minutes the average heart rate during the cycling session with music ( 169.7 beats/min) was slightly higher than the cycling session without music (167.7 beats/min). The heart rate findings in this study are similar to those reported in the following research, ${ }^{5,7,10}$ where no significant difference in heart rate was found between the session with music and without music.

This study showed that music had no influence on the instantaneous Borg scale ratings. The results of this study are in contrast with findings of Nethery, ${ }^{5}$ Potteiger et al. ${ }^{7}$ and Szabo et al. ${ }^{10}$ The latter studies all found that music resulted in a reduced rating of perceived exertion. A possible reason for this contrast may be differences in the subject groups used. Our subject group consisted of trained and disciplined cyclists participating in a study using cycling as the mode of exercise. Other studies used mostly untrained subject groups or groups of heterogeneous athletes, some of whom were unfamiliar with the mode of exercise used in the study. Our cycling sessions only lasted for 20 minutes (excluding the warm-up session). Since the Borg scale became more pronounced with time, it is likely that had the study period gone on for longer the results might have been different. Another possible reason could be that the subjects were working at a relatively high intensity $\left(80 \%\right.$ of the $\left.\mathrm{VO}_{2 \max }\right)$. It is possible that at this intensity the subjects' physiological cues could overpower distraction stimuli such as music.

Contrary to Szmedra and Bacharach, ${ }^{9}$ who showed the exercise session with music to have a smaller change in plasma lactate concentration, compared with the exercise session without music, this study showed that there was no significant difference in plasma lactate concentration between the groups.

\section{Conclusion}

Listening to music while performing submaximal cycling resulted in no physiological benefit. However, it may allow individuals to alter their overall perception of effort while cycling. By acting as a positive emotional distracter, music may motivate the cyclist to increase adherence to training, allowing the to train longer and more efficiently.

\section{Acknowledgements}

This research received no external financial assistance. The following people and institutions are acknowledged: Nomonde Molebatsi for her assistance in the exercise laboratory, and the School of Physiology, Health Science Faculty, University of the Witwatersrand, for allowing the Exercise Laboratory to be used and for supporting many of the costs of the study.

\section{REFERENCES}

1. Atkinson G, Wilson D, Eubank M. Effects of music on work-rate distribution during a cycling time trial. Int J Sports Med 2004; 25: 611- 5.

2. Becker N, Brett $S$, Chambliss $C$ et al. Mellow and frenetic antecedent music during athletic performance of children, adults and seniors. Percept Mot Skills 1994; 79: 1043-6.

3. Boutcher SH, Trenske M. The effects of sensory deprivation and music on perceived exertion and affect during exercise. Journal of Sport and Exercise Psychology 1990; 12: 167-76.

4. Grant S, Aitchison T, Henderson E, et al. A comparison of the reproducibility and the sensitivity to change of visual analogue scales, Borg scales, and Likert scales in normal subjects during submaximal exercise. Chest 1999; 116: 1208- 17.

5. Nethery VM. Competition between internal and external sources of information during exercise: influence on RPE and the impact of the exercise load. $J$ Sports Med Phys Fitness 2002; 42: 172-18.

6. Pate RR, Blair SN, Durstine JL. Guidelines for Exercise Testing and Prescription, 4th ed. Philadelphia and London: Lea \& Febiger, 1991.

7. Potteiger JA, Schroeder JM, Goff KL. Influence of music on ratings of perceived exertion during 20 minutes of moderate intensity exercise. Percept Mot Skills 2000, 91: 848-54.

8. Pujol TJ, Langenfeld ME. Influence of music on Wingate anaerobic test performance. Percept Mot Skills 1999; 88: 292-6.

9. Szmedra L, Bacharach DW. Effect of music on perceived exertion, plasma lactate, norepinephrine and cardiovascular hemodynamics during treadmill running. Int J Sports Med 1998; 19: 32-7.

10. Szabo A, Small A, Leigh M. The effects of slow-and fast-rhythm classical music on progressive cycling to voluntary physical exhaustion. J Sports Med Phys Fitness 1999; 39: 220-5.

11. White VB, Potteiger JA. Comparison of passive sensory stimulations on RPE during moderate intensity exercise. Percept Mot Skills 1996; 82: 819-25. 